\title{
Indoor secondary organic aerosols formation from ozonolysis of monoterpene: An example of d-limonene with ammonia and potential impacts on pulmonary inflammations
}

\author{
Xinyi Niu ${ }^{\text {a,b }}$, Steven Sai Hang Ho ${ }^{\text {b,c }}$, Kin Fai Ho ${ }^{\mathrm{e}}$,Yu Huang ${ }^{\text {b,d* }}$, Junji Cao ${ }^{\text {b,d,f* }}$, Zhenxing
}

Shen ${ }^{\mathrm{g}}$, Jian Sun ${ }^{\mathrm{g}}$, Xiumei Wang ${ }^{\mathrm{h}}$, Yu Wang ${ }^{\text {h }}$, Shuncheng Lee ${ }^{\mathrm{i}}$, Rujin Huang ${ }^{\mathrm{b}, \mathrm{d}}$

${ }^{a}$ School of Human Settlements and Civil Engineering, Xi'an Jiaotong University,
Xi'an, China
${ }^{b}$ Key Lab of Aerosol Chemistry \& Physics, Institute of Earth Environment, Chinese
Academy of Sciences, Xi'an, China
Division of Atmosphere Sciences, Desert Research Institute, Reno, NV89512, United States

${ }^{d}$ State Key Lab of Loess and Quaternary Geology (SKLLQG), Institute of Earth Environment, Chinese Academy of Sciences, Xi'an 710061, China

${ }^{e}$ The Jockey Club School of Public Health and Primary Care, The Chinese University of Hong Kong, Hong Kong, China

${ }^{f}$ Institute of Global Environmental Change, Xi'an Jiaotong University, Xi'an, China

${ }^{g}$ Department of Environmental Sciences and Engineering, Xi'an Jiaotong University, $X i$ 'an, China

${ }^{h}$ School of Pharmacy, Xi'an Jiaotong University, Xi'an, China

${ }^{i}$ Department of Civil and Structural Engineering, Research Center for Environmental Technology and Management, The Hong Kong Polytechnic University

* Corresponding author: Key Lab of Aerosol Chemistry \& Physics, Institute of Earth Environment, Chinese Academy of Sciences, Xi'an, 710061, China.

E-mail addresses: huangyu@ieecas.cn (Y. Huang), cao@loess.llqg.ac.cn (J.J. Cao). Telephone number: +86-029-62336261; +86-029-62336205

Tax number: 86-029-62336234 


\section{Abstracts:}

Monoterpene is one class of biogenic volatile organic compounds (BVOCs) which widely presents in household cleaning products and air fresheners. It plays reactive role in secondary organic aerosols (SOAs) formation with ozone $\left(\mathrm{O}_{3}\right)$ in indoor environments. Such ozonolysis can be influenced by the presence of gaseous pollutants such as ammonia $\left(\mathrm{NH}_{3}\right)$. This study focuses on investigations of ozone-initiated formation of indoor SOAs with d-limonene, one of the most abundant indoor monoterpenes, in a large environmental chamber. The maximum total particle number concentration from the ozonolysis in the presence of $\mathrm{NH}_{3}$ was $60 \%$ higher than that in the absence of $\mathrm{NH}_{3}$. Both of the nuclei coagulation and condensation involve in the SOAs growth. The potential risks of pulmonary injury for the exposure to the secondary particles formed were presented with the indexes of tumor necrosis factor- $\alpha$ (TNF- $\alpha$ ), interleukin-6 (IL-6) and interleukin-10 (IL-10) expression levels in bronchoalveolar lavage fluid (BALF) upon intratracheal instillation in mice lung for 6 and 12 hours. The results indicated that there was $22-39 \%$ stronger pulmonary inflammatory effect on the particles generated with $\mathrm{NH}_{3}$. This is a pilot study which demonstrates the toxicities of the indoor SOAs formed from the ozonolysis of a monoterpene.

Key words: indoor air quality; secondary organic aerosols; monoterpene; ammonia effect; pulmonary inflammation 


\section{Introduction}

Indoor air quality (IAQ) has been drawn more public and governmental authorities' concern in recent years. Hundreds of illness outbreaks, directly or indirectly related to IAQ, occurred in our societies, where include offices, schools, and open accessible buildings (Cao et al., 2012; Che et al., 2015; Godish, 1989; Jiang and Bell, 2008). Higher levels of many pollutants were often seen indoor than outdoor (He et al., 2005; Jones et al., 2000; Parker et al., 2008; Zhou et al., 2016). The United States Environmental Protection Agency (U.S. EPA) highlighted that people spend approximately $90 \%$ of their lifetime in indoor environments. Indoor exposure is thus particularly important. Many epidemiological studies proved that either short- or long-term pulmonary exposures to toxic respirable particulate matter (PM) are highly associated with increases of morbidity and mortality (Huang et al., 2012a; Lin et al., 2005; Madureira et al., 2015; Ostachuk et al., 2008).

Ozone $\left(\mathrm{O}_{3}\right)$ and ammonia $\left(\mathrm{NH}_{3}\right)$ are important indoor gas pollutants. The $\mathrm{O}_{3}$ is often generated from electric devices such as office equipment (e.g., photocopiers and laser printers) and ozone/ion generator, and its indoor levels (with a typical range of 10-100 ppbv) can be greatly influenced by outdoor-to-indoor conversion subjected to the efficiency of air exchange (Britigan et al., 2006; Waring and Siegel, 2011a, 2013). Indoor $\mathrm{NH}_{3}$ is mainly emitted from household cleaners, refrigeration units, tobacco smoke and addition urea-based antifreeze admixtures (Bai et al., 2006; Koistinen et al., 2008; Pei et al., 2016; Sarigiannis et al., 2011).

Monoterpenes, a well-known class of biogenic volatile organic compounds 
(BVOCs) with a basic chemical formula of $\mathrm{C}_{10} \mathrm{H}_{16}$, are widely used as an active ingredient or a fragrance in cleaning products and air fresheners (Singer et al., 2006a; Singer et al., 2006b). d-limonene and $\alpha$-pinene are the two most abundant monoterpenes present in indoor environment (Brown et al., 1994). Leungsakul et al. (2005) outlined secondary organic aerosols (SOAs) formation mechanism from the chain reactions of d-limonene in presence of oxides of nitrogen and natural sunlight in an environmental chamber. The important role of $\mathrm{O}_{3}$ in the gas-to-particle reactions with surface-absorbed d-limonene onto the SOAs was demonstrated by Waring and Siegel (2013) as well. The generations of SOAs between indoor $\mathrm{O}_{3}$ and a single terpenoids were investigated in many studies, in which few focused on a mixture of BVOCs emitted from the household products (Huang et al., 2011a; Lamorena and Lee, 2008; Nazaroff and Weschler, 2004; Waring et al., 2011b).

Exposures to indoor $\mathrm{O}_{3}$ and oxidized products have connections with morbidity/mortality (Breysse et al., 2013; Tamas et al., 2006; Weschler, 2006). The impacts on the irritants formation from limonene and isoprene in functions of reaction time, relative humidity $(\mathrm{RH})$ and initial concentrations of the reactants were investigated (Wilkins et al., 2003). Rohr et al. (2002) suggested that the terpene/ozone reaction products may have moderate-lasting adverse effects on both the upper airways and pulmonary regions to human. In addition, more evidences showed that PM inhalation can perpetually damage pulmonary and cardiovascular systems (Astort et al., 2014; Bates et al., 2015; de Brito et al., 2014; Magnani et al., 2011); A wide variety of toxicities caused were also reported in vivo and in vitro studies, by means of 
inflammatory cytokines induction as exposure response to different PM components, (Ho et al., 2016; Leung et al., 2014; Michael et al., 2013; Seagrave et al., 2006). However, those studies seldom discussed on the pulmonary injury related to the ozonolysis of BVOCs.

There is little work on the investigation of SOAs formation between $\mathrm{O}_{3}$ and BVOCs in the presence of $\mathrm{NH}_{3}$; and, more particularly, their potential health impact on human respiratory system is still a lack. In this study, d-limonene was used to be an example to demonstrate the indoor SOAs formation from the ozonolysis of monoterpene and the effects of presence of $\mathrm{NH}_{3}$ on the basis of chains of chamber experiments. With the collections of PM onto filter matrix, the degrees of pulmonary injury of the exposures to the secondary particles formed were presented by the indexes of tumor necrosis factor- $\alpha$ (TNF- $\alpha$ ), interleukin-6 (IL-6) and interleukin-10 (IL-10) expression levels in bronchoalveolar lavage fluid (BALF). The theme of this research is critical and advances our knowledge on their potential health risks for those abundant indoor pollutants.

\section{Methods}

\subsection{Environmental chamber}

The experiments were conducted in a stainless-steel environmental chamber $(3.2 \mathrm{~m}$ $\times 3.2 \mathrm{~m} \times 2.5 \mathrm{~m}$ ). The effective volume is $18.26 \mathrm{~m}^{3}$ with a surface area to volume ratio of $2.87\left(\mathrm{~m}^{2} / \mathrm{m}^{-3}\right)$. The schematic diagram of the chamber is shown in Fig. 1 and details of the operating principle were presented in our previous publication (Huang et 
al., 2011a). Prior to each experiment, the chamber interior surfaces were fully cleaned by a sponge mop, and then adjusted and maintained to desired physical conditions [air exchange rate $(\mathrm{ACH})$ of $0.36 / \mathrm{h}$, relative humidity $(\mathrm{RH})$ of $75 \%$ and temperature $(\mathrm{T})$ of $23^{\circ} \mathrm{C}$ for 4 hours, simulating to a real indoor environment. The background level for total volatile organic compounds (TVOCs) and individual VOC were below 10 $\mu \mathrm{gm}^{-3}$ and $2 \mu \mathrm{gm}^{-3}$, respectively (Huang et al., 2011b; USEPA, 1999).

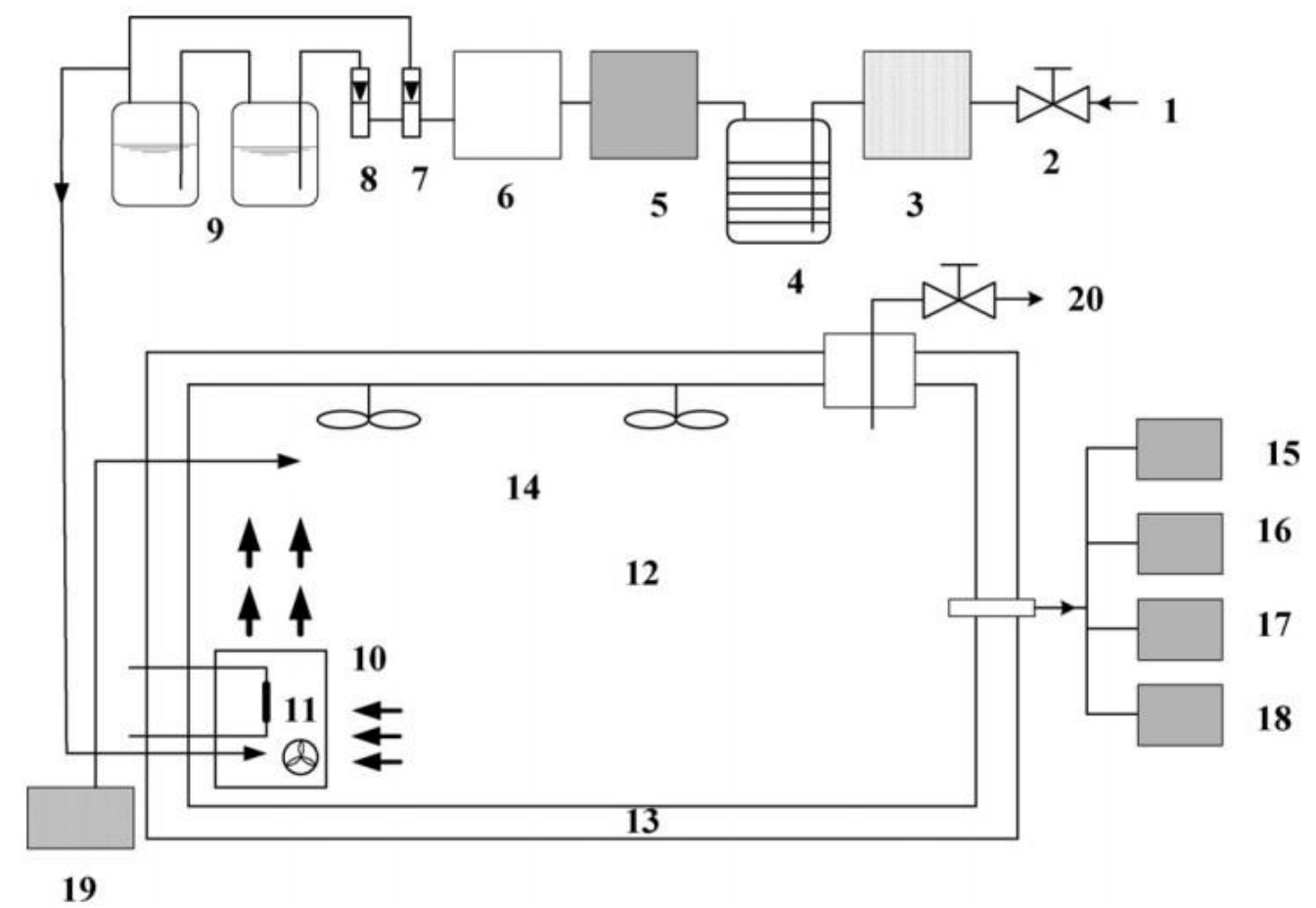

Fig. 1 Schematic diagram of the chamber study set-up: (1) air inlet; (2) valve; (3) blower; (4) active charcoal filters; (5) HEPA filters; (6) mass flow controllers; (7) flow controller dry air; (8) flow controller wet air; (9) humidifier; (10) rotating cylinder; (11) heating unit; (12) large environmental test chamber; (13) insulation layer; (14) mixing fan; (15) SMPS/CPC; (16) ozone monitor; (17) ammonia monitor; (18) $\mathrm{H}_{2} \mathrm{O}_{2}$ analyzer; (19) ozone generator; and (20) air outlet.

\subsection{Gas introductions and experiment process}

d-limonene was chosen as a representative of monoterpene in this study. The initial concentration of d-limonene inside the chamber was set as 200 ppbv, which was prepared by injection of standard gaseous by sampling bag method. A 40-L Tedlar air 
bag (SKC Inc., Eighty Four, PA, USA) was fully cleaned and filled with air generated by a zero air supply (Model 111, Thermo Environmental Instruments, Frankin, MA, USA). Sixty microliter of d-limonene (Technical Grade, Chem Service, West Chester, PA, USA) was injected into the air bag with a $100 \mu 1$ syringe (Hamilton, Reno, Nevada, USA). The liquid was completely vaporized in an oven at $70^{\circ} \mathrm{C}$. The airs in the bag was then introduced into the centre of the chamber through a plastic tube by an aircheck sampler (Model 224-44XR, SKC Inc.) at a flow rate of $1 \mathrm{~L} / \mathrm{min}$.

$\mathrm{O}_{3}$ was produced by an ozone-generator (Model 2001, Jelight Company Inc., Irvine, CA, USA), which was fed with purified air at a pressure of 20 psi. Initially, the $\mathrm{O}_{3}$ was introduced into the chamber with a constant flow rate of $63 \mathrm{ml} / \mathrm{min}$. After 30 minutes, the gaseous d-limonene prepared in the sampling bag was then injected. The $\mathrm{O}_{3}$ supply was terminated 120 minutes after the injection of d-limonene. In the $\mathrm{NH}_{3}$ effect tests, $\mathrm{NH}_{3}$ was introduced into the chamber 30 minutes before the d-limonene injection. The $\mathrm{NH}_{3}$ gas stream was directly supplied from a compressed gas cylinder ( $\mathrm{N}_{2}$ balance, $99.999 \%$, BOC Gas, UK). Each experiment was repeated 3 times to demonstrate the reproducibility.

\subsection{Sampling and analytical methods}

The variations of $\mathrm{O}_{3}, \mathrm{NH}_{3}$ and TVOC concentrations and particle number size distribution were measured in the chamber. The $\mathrm{NH}_{3}$ level was monitored by connecting the air from the chamber to a thermal oxidizer (Model 501, API, San Diego, CA, USA), which oxidized ammonia to nitrogen monoxide (NO) at $825^{\circ} \mathrm{C}$, and finally measured by a Chemiluminescent $\mathrm{NO}_{\mathrm{x}}$ Analyzer (Model 201A, API). The 
thermal oxidizer was properly calibrated using a certified cylinder of $\mathrm{NH}_{3}$. The $\mathrm{O}_{3}$ concentration was monitored by a photometric ozone analyzer (Model 400E, Teledyne Instruments, San Diego, CA, USA). A ppbRAE monitor (Model PGM 7240, RAE Systems, Sunyvale, CA, USA) was used to measure the TVOCs concentrations. Particle size distribution of PM with the diameters ranging from 14.1 to $737 \mathrm{~nm}$ was measured by a scanning mobility particle sizer (SMPS) system with a differential mobility analyzer (Model 3080, TSI Inc., MN, USA) coupled to a condensation particle counter (Model 3022, TSI Inc.). All of the real-time instruments were well-calibrated before uses. The concentrations of $\mathrm{O}_{3}, \mathrm{NH}_{3}$ and TVOCs were recorded at 1-min interval, while particle number size distribution was monitored at 4-min interval continuously.

$\mathrm{PM}_{2.5}$ formed in the reaction between $\mathrm{O}_{3}$ and d-limonene was collected with a mini-volume sampler (Airmetrics, Springfield, OR, USA) in the environmental chamber. The sampling inlet was set at $1.2 \mathrm{~m}$ above ground level and the actual volumetric flow rate was $5 \mathrm{~L} / \mathrm{min}$. The $\mathrm{PM}_{2.5}$ was collected on $47 \mathrm{~mm}$ quartz microfiber filters (Whatman, Germany), which were preheated at $900{ }^{\circ} \mathrm{C}$ for $3 \mathrm{~h}$. The sample contained filter was unloaded from the filter holder immediately after the sampling and stored in a refrigerator at $4{ }^{\circ} \mathrm{C}$ to avoid evaporation of volatile compounds. Before gravimetric measurement, all filters were maintained in a condition chamber with a $50 \% \mathrm{RH}$ at $25{ }^{\circ} \mathrm{C}$ for over $24 \mathrm{~h}$. The mass of $\mathrm{PM}_{2.5}$ were obtained by weighing the filters prior and after the sample collection, respectively, on a microbalance (M5, Sartorius, Göttingen, Germany) with an accuracy of $1 \mu \mathrm{g}$. Each 
filter weighed at least twice to ensure the reproducibility with a d-value less than $0.015 \mathrm{mg}$. Operation filed blanks were collected to investigate organics passively absorbed onto the filter during sampling. The amounts of analytes on the sample filters were deducted from those on the blanks to reduce the error due to positive absorption artifact.

\subsection{Animal exposure to PM and model of acute lung injury (ALI)}

Male Kunming mice (20-25 g) were purchased from the Experimental Animal Center, Xi'an Jiaotong University (Xi'an, China). They were maintained under standard conditions of $\mathrm{RH}$ of $55 \pm 5 \%$, a $12 \mathrm{~h}$ light/dark cycle, and at $23 \pm 2{ }^{\circ} \mathrm{C}$ with standard laboratory chow and water. All experimental handing and safety procedures were in accordance with guidelines recommended by the National Institute of Health (Institute of Laboratory Animal Resources et al., 1985).

All PM and filed blank samples were extracted with $10 \mathrm{ml}$ distilled-deionized water (18.2M $\Omega$ resistivity) using ultra-sonication for $60 \mathrm{~min}$, and then shaken with a mechanical shaker for $60 \mathrm{~min}$. A total of 48 mice were randomly divided into four groups for the tests, including (i) experimental control, (ii) field blank, (iii) ozonolysis in the presence of $\mathrm{NH}_{3}$, and (iv) ozonolysis in the absence of $\mathrm{NH}_{3}$. The mice were treated by intranasal instillation with $100 \mu \mathrm{L}$ of the autoclaved phosphate buffered saline (PBS) solution (for the control group), the suspension liquid from the blank samples (for the blank group), and the suspension of $\mathrm{PM}_{2.5}$ samples collected in absence and absence of $\mathrm{NH}_{3}$. They were then immobilized in a $60^{\circ}$ inclined supine position while the same dose of $50 \mu \mathrm{g} / \mathrm{ml}$ suspension was delivered dropwisely to the 
nares by an automatic pipette. The acute pulmonary injuries to mice by $\mathrm{PM}_{2.5}$ formed in the chambers were euthanized after exposures for $6 \mathrm{~h}$ and $12 \mathrm{~h}$ respectively.

\subsection{Collections of bronchoalveolar lavage fluid $(B A L F)$ and BALF analysis}

After the intranasal stimulation for 6 and $12 \mathrm{~h}$ respectively, the collections of bronchoalveolar lavage fluid (BALF) were repeatedly performed three times through a tracheal cannula with autoclaved PBS. Each sample was instilled up to a total volume of $1.3 \mathrm{ml}$. The recovery rate of BALF was $>90 \%$. The collected BALF was immediately centrifuged at $1500 \mathrm{rpm}$ at $4{ }^{\circ} \mathrm{C}$ for $10 \mathrm{~min}$ and the supernatants were collected for inflammatory evaluation.

The enzyme-linked immunosorbent assay (ELISA) kits for mice of TNF- $\alpha$, IL-6, and IL-10 tests were obtained from R\&D Systems (Minneapolis, MN, USA). The levels of TNF- $\alpha$, IL-6, and IL-10 in BALF were determined with the corresponding ELISA kits according to the manufacturer's instructions. In brief, $100 \mu \mathrm{L}$ of the samples were loaded and added up with biotin conjugated secondary antibodies. The streptavidin-HRP and substrate solution were used as indicators for the reactions. The products were measures at an absorbance of $450 \mathrm{~nm}$ with an ELISA reader (Molecular Devices, Sunnyvale, CA, USA).

\subsection{Statistical analysis}

All statistical analyses were using SPSS software (version 12.0; SPSS Inc., Chicago, IL, USA). One-way analysis of variance (ANOVA) was applied for statistical significance of different groups. The level of significance for all statistical analyses was set as $\mathrm{p}<0.05$.

\section{Results and discussion}




\subsection{Ozone and ammonia variation}

Fig. 2 presents the variations of $\mathrm{O}_{3}$ and $\mathrm{NH}_{3}$ concentrations in the environmental chamber. In the test without $\mathrm{NH}_{3}, \mathrm{O}_{3}$ was introduced into the conditioned chamber 30 minutes before the introduction of d-limonene (Phase I). The $\mathrm{O}_{3}$ level steadily increased to above $60 \mathrm{ppbv}$. In Phase II, the injection of d-limonene began, and the concentration of $\mathrm{O}_{3}$ slightly increased to $\sim 70 \mathrm{ppbv}$ and then dropped to $60 \mathrm{ppbv}$ in 20 minutes. This can be explained by the oxidation off d-limonene, which had a consumption of $\mathrm{O}_{3}$. The injection of d-limonene to the chamber stopped in the beginning of Phase III. The $\mathrm{O}_{3}$ level dropped a little to 50 ppbv but then rose to 100 ppbv in 100 minutes due to continuous complement of $\mathrm{O}_{3}$. The introduction of $\mathrm{O}_{3}$ was terminated in Phase IV. There was thus a continuous and shape decrease in $\mathrm{O}_{3}$ level while the concentration of TVOCs was still being reduced (TVOCs $<100 \mathrm{ppbv}$ ). Rather than uptake by the oxidation, $\mathrm{O}_{3}$ can be self-degraded in the chamber or absorbed by inter-walls of the chamber. The decreasing rate of $\mathrm{O}_{3}$ became steady in the last 60 minutes. It could be ascribed to almost no reaction with d-limonene.

In the demonstration tests for $\mathrm{NH}_{3}$ effect, $\mathrm{NH}_{3}$ was continuously supplied into the chamber with $\mathrm{O}_{3}$ since the start in Phase I. While d-limonene was injected in Phase II, there was a more rapidly decline in $\mathrm{O}_{3}$ level (to 55ppbv) compared to the case without $\mathrm{NH}_{3}$. The result demonstrated that more $\mathrm{O}_{3}$ uptake in the oxidation of d-limonene in the presence of $\mathrm{NH}_{3}$, suggesting the strong catalytic effects of $\mathrm{NH}_{3}$. This function can be further confirmed by the phenomenon in Phase IV, while the introduction of both $\mathrm{O}_{3}$ and $\mathrm{NH}_{3}$ were terminated. In the coexistence of $\mathrm{NH}_{3}$, more remained $\mathrm{O}_{3}$ was 
consumed for the reaction of d-limonene, resulting in a faster decline on the $\mathrm{O}_{3}$ concentration compared with the case without $\mathrm{NH}_{3}$.

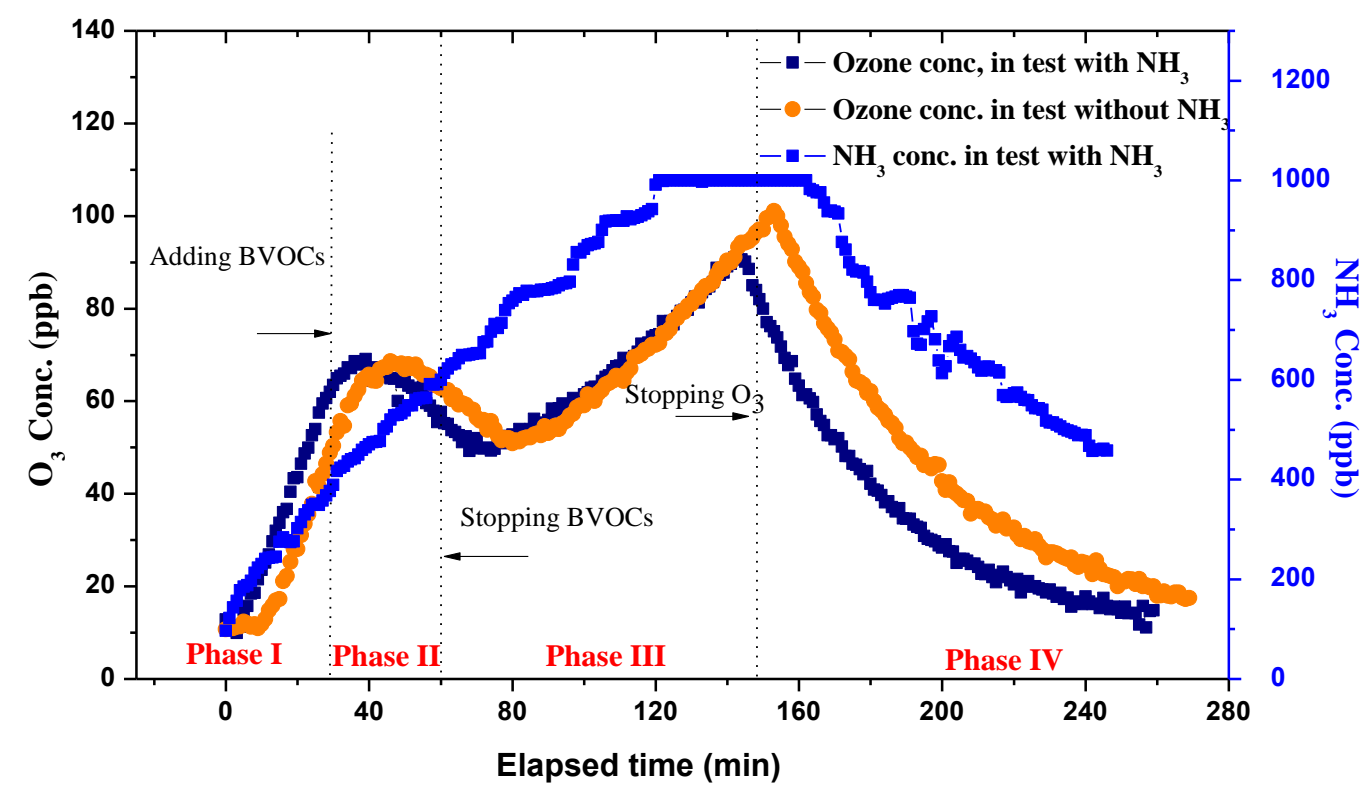

Fig. 2 Ozone and ammonia concentration variations during experiment with the presence of $\mathrm{NH}_{3}$ and without the presence of $\mathrm{NH}_{3}$

\subsection{Effects of $\mathrm{NH}_{3}$ on SOAs formation}

Fig. 3 shows the particle size distributions with a diameter of 14.1-737 nm from the ozonolysis of d-limonene with and without the presence of $\mathrm{NH}_{3}$ measured by SMPS. While the introducing of d-limonene into the $\mathrm{O}_{3}$ atmosphere, particles formations were seen at once. More evident "burst" growth of SOAs was observed in the presence of $\mathrm{NH}_{3}$, especially with particle diameter ranging from 50 to $200 \mathrm{~nm}$, of which these fine particles were dominant to the total particle number concentrations in the chamber atmosphere. Previous studies demonstrated that gasphase SOA formation commonly occurred from the reactions between surface-adsorbed d-limonene and $\mathrm{O}_{3}$ in indoor environment (Waring et al., 2011b), and the subsequent 
intermediate and by-products could also advance with the growth rate (Sarwar and Corsi, 2007). This finding is also consistent with the previous reports on the formation of SOAs that the particles could be generated from household product emissions (Chen and Hopke, 2010; Destaillats et al., 2006; Rossignol et al., 2013).

In Phase I, the total particle number concentration kept at a low value (below $10^{3} \mathrm{Hcm}^{-3}$ ), indicating that there were no any particle formations. When d-limonene was injected into the chamber in Phase II, an obvious growth of particles could be seen, especially for the particles with diameter ranging from 10 to $300 \mathrm{~nm}$. Proceeding of the reactions with $\mathrm{NH}_{3}$, the particle number concentration (in diameter ranging from $100 \mathrm{~nm}$ to $200 \mathrm{~nm}$ ) increased rapidly to the highest level of $5.94 \times 10^{5}$ $\# \mathrm{~cm}^{-3}$ (Fig. 3a), which was $55 \%$ higher than the maximum value of that in the absence of $\mathrm{NH}_{3}$ (Fig. 3b).

In Phase III, the growth of SOAs continued but then reduced slightly. The highest particle number concentrations were as high as $5.83 \times 10^{5} \mathrm{Hcm}^{-3}$, which was also much greater than the maximum without $\mathrm{NH}_{3}$. In comparison, the particles ranging from 100 to $200 \mathrm{~nm}$ in diameter had relatively higher abundances than others in the formation. Due to the degradation and consumption of $\mathrm{O}_{3}, \mathrm{NH}_{3}$ and d-limonene and ventilation in the chamber environment, there was a huge decline in particle number concentration to $1.0 \times 10^{4} \mathrm{\# cm}^{-3}$ to $1.0 \times 10^{5} \mathrm{\# cm}^{-3}$ with a maximum, with size ranging from 180 to $210 \mathrm{~nm}$. 

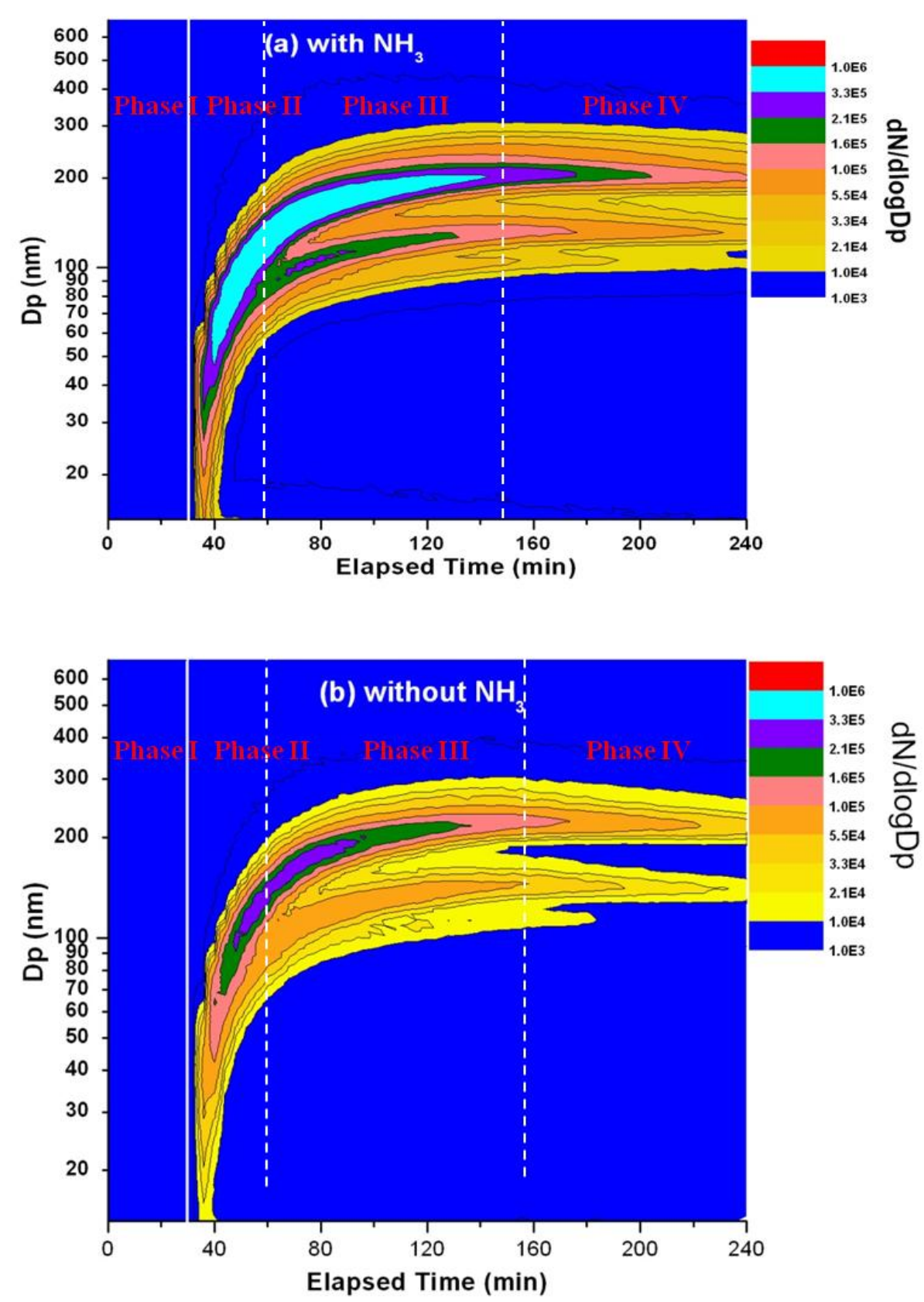

Fig. 3 Temporal evolutions of particle size distributions with a diameter of 14.1-737 nm measured with the SMPS equipment with (a) and without (b) $\mathrm{NH}_{3}$ presence in the initial chamber atmosphere

The presence of $\mathrm{NH}_{3}$ in the reaction systems could enhance the oxidation of d-limonene, and thereby generated much more SOAs. Huang et al. (2012b) demonstrated that the extent of $\mathrm{NH}_{3}$ effect on SOAs formation from the ozonolysis of BVOCs was component-dependent. The results from this study proved the significant of ultrafine particles formations in the coexistence of $\mathrm{NH}_{3}$, leading to a 
better understanding of indoor ozone chemistry.

$\mathrm{Na}$ et al (2006) suggested a detailed explanation to the impact of SOAs formations with the presence of $\mathrm{NH}_{3} . \mathrm{NH}_{3}$ can interact with gas-phase organic acids, products from oxidation of organics, to form condensable salts (e.g., ammonium salts) and thereby enhance the SOAs formation. As shown in Na et al (2007), the condensable salts could be formed from the $\alpha$-pinene ozonolysis system while $\mathrm{NH}_{3}$ was present. It has been generally found that low volatility organic acids such as pinic acid and pinonic acid could be generated during the oxidations of biogenic hydrocarbons (Kavouras et al., 1999; Yu et al., 1999). In our chamber reaction system, the organic acids were also expected to be the major by-products from the ozonolysis of d-limonene which could react with $\mathrm{NH}_{3}$ to form the condensable salts of low volatility, contributing to the increases of the particle number concentrations.

\subsection{Effect of $\mathrm{NH}_{3}$ on particles number concentrations and geometric mean}

\section{diameters}

The variations of total particle number concentrations with and without $\mathrm{NH}_{3}$ presence are shown in Fig. 4 (a). The $\mathrm{O}_{3}$ concentration is plotted as a reference. The highest total particle number concentration was $1.4 \times 10^{5} \mathrm{\# cm}^{-3}$ in the presence of $\mathrm{NH}_{3}$, which was $60 \%$ higher than that without $\mathrm{NH}_{3}$. The higher concentration suggests that $\mathrm{NH}_{3}$ can enhance gas-to-particle conversion and promote new formations of particles. $\mathrm{NH}_{3}$ may contribute to the condensation of vapors onto the existing particles and hence lead the coagulation of particles in the nuclei mode. The highest total particle numbers were seen few minutes after d-limonene was 
introduced into the chamber at the initial stage of Phase II. This suggests that the SOAs formation underwent in a very short time at the defined conditions. In the presence of $\mathrm{NH}_{3}$, the reactions were more energetic and rapid in production of the particles. Decline trends in the total particle number concentrations were also seen from the maximum values either presence or absence of $\mathrm{NH}_{3}$. Less formation of SOAs occurred in the later phases since more and more d-limonene had been consumed or ventilated, additional with the termination of introduction of $\mathrm{O}_{3}$ and $\mathrm{NH}_{3}$ in Phase IV.

Fig. 4 (b) shows the geometric mean diameters of the particles formed in the chamber experiment. The mean diameters of particles increased during the ozonolysis taken place. In the presence of $\mathrm{NH}_{3}$, a slightly larger mean diameter was observed, which is consistent with the finding from our previous study (Huang et al., 2012). In Phase I, only trace amount of particles, identified as the background, were presented in the chamber. The geometric mean diameters of these particles were between $120-140 \mathrm{~nm}$ in the presence of $\mathrm{NH}_{3}$, which were slightly higher than those without $\mathrm{NH}_{3}$ (in a range of 100-120nm). However, these should not be related to any SOAs formation as the organic levels were very low in the clean environment. Once d-limonene was introduced, the geometric mean diameters of the particles reduced to $32.5 \mathrm{~nm}$. Along the elapsed times in Phase II, the particle sizes continuously enlarged which had diameters close to $150 \mathrm{~nm}$ until the end of this phase. This can be ascribed with the nuclei coagulation and condensation reactions, leading to absorption onto the preexisting particles. More particularly, the particle diameters were slightly lower 
in the presence of $\mathrm{NH}_{3}$ than those formed without $\mathrm{NH}_{3} . \mathrm{NH}_{3}$ can activate the ozonolysis that has a higher tendency to form new and small particles in the chamber, instead of the condensation of newly-generated particles onto the pre-existed particles. Such particle growth was continuous but had a slower rate even though the introduction of d-limonene terminated at the beginning of Phase III. The activity of ozonolysis obviously reduced the geometric mean particle diameters raised to 180 nm. In the last stage of Phase IV, the reaction almost complete and thus, the geometric mean particle diameters only kept at a constant level. 
(a)
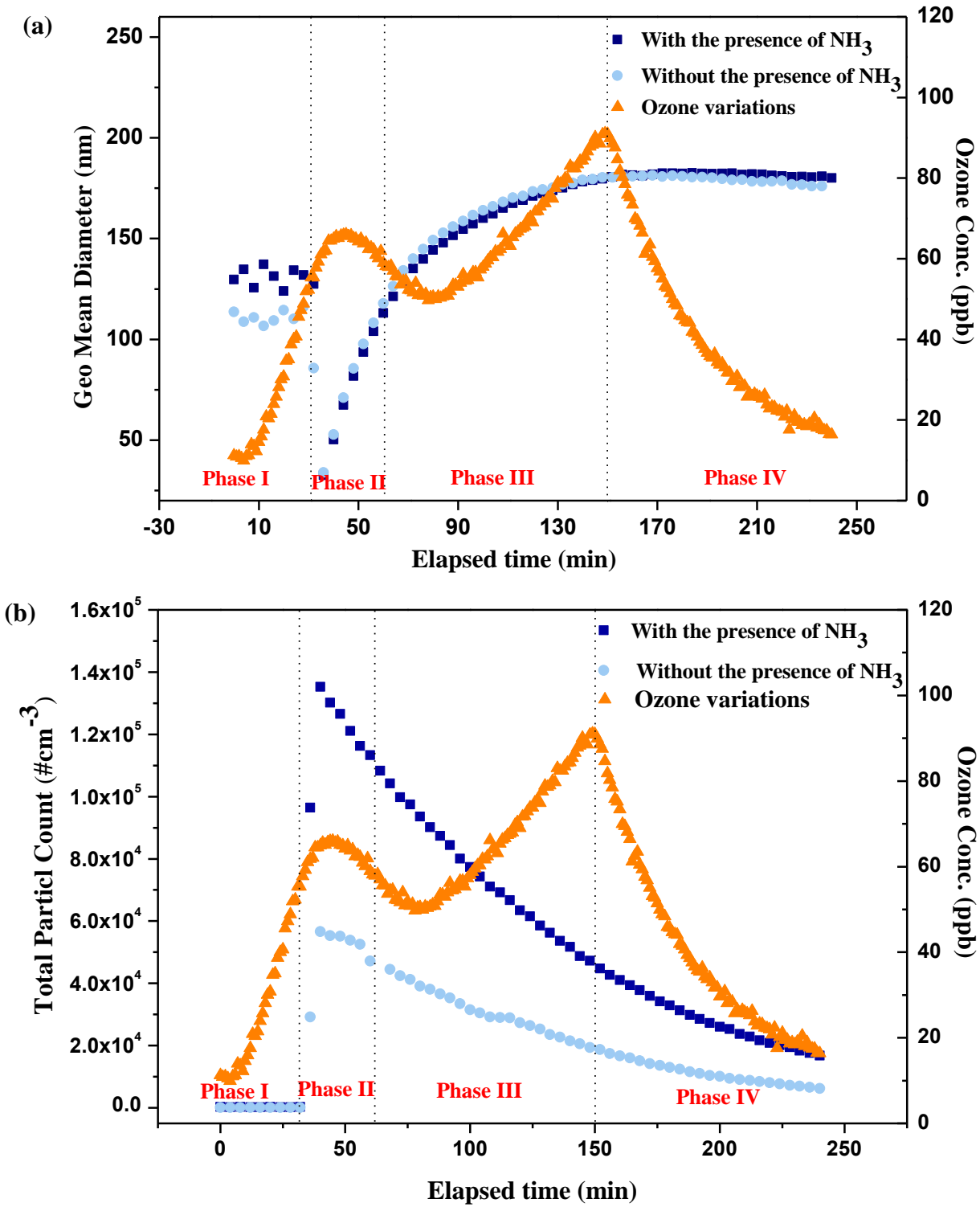

Fig. 4 Ozone concentration and (a) total particle number concentration of particles; (b) geometric mean diameters of particles with and without $\mathrm{NH}_{3}$ presence in the initial chamber atmosphere

\subsection{Effect of $\mathrm{NH}_{3}$ on toxicity of the particle formed}

Fig.5 gives a schematic overview of the biological responses in mice BALF upon treatment with the different PM suspensions. The production of TNF- $\alpha$, IL-6 and IL-10 in the PBS blank control group has no significant difference with the blank group, while the blank samples still have slightly effect on inflammation, which may caused by quartz fibers and initial elements in the filter. However, the levels of 
TNF- $\alpha$, IL-6, and IL-10 in BALF were markedly elevated after PM samples instillation both with and without the presence of $\mathrm{NH}_{3}$ in $6 \mathrm{~h}$ and $12 \mathrm{~h}$, which were significantly different from control group $(\mathrm{p}<0.05$ or $\mathrm{p}<0.01)$. In addition, inflammatory cytokines levels of TNF- $\alpha$, IL-6 and IL-10 reached a maximum at $6 \mathrm{~h}$ and then gradually declined at $12 \mathrm{~h}$. Comparing to PM samples without the presence of $\mathrm{NH}_{3}$, the levels of TNF- $\alpha$ and IL-6 were $22 \% \sim 39 \%$ higher than the levels in the samples with $\mathrm{NH}_{3}$, while anti-inflammatory cytokine of IL-10 reduced when exposed to $\mathrm{NH}_{3}$. 
(a)

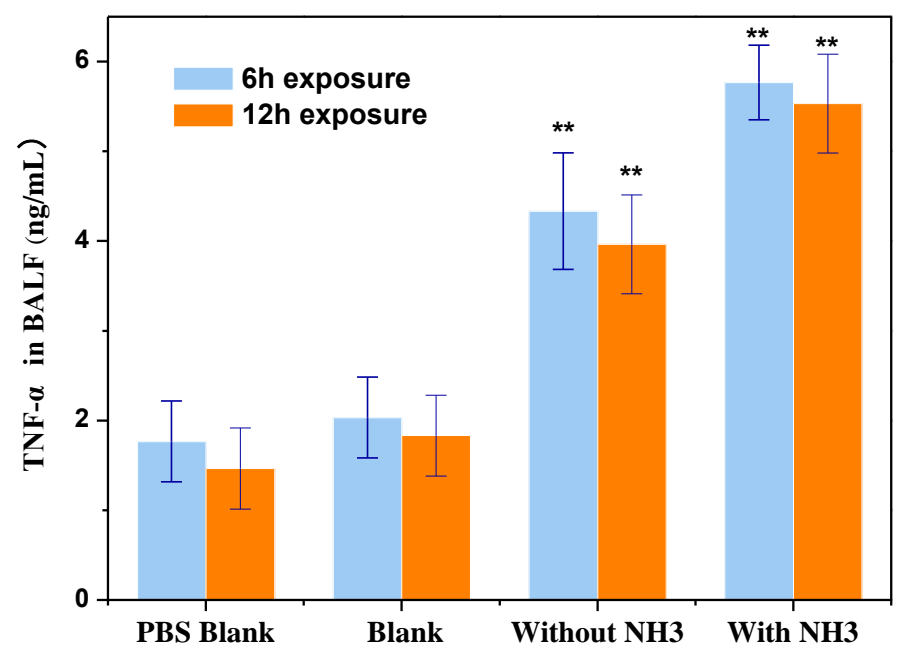

(b)

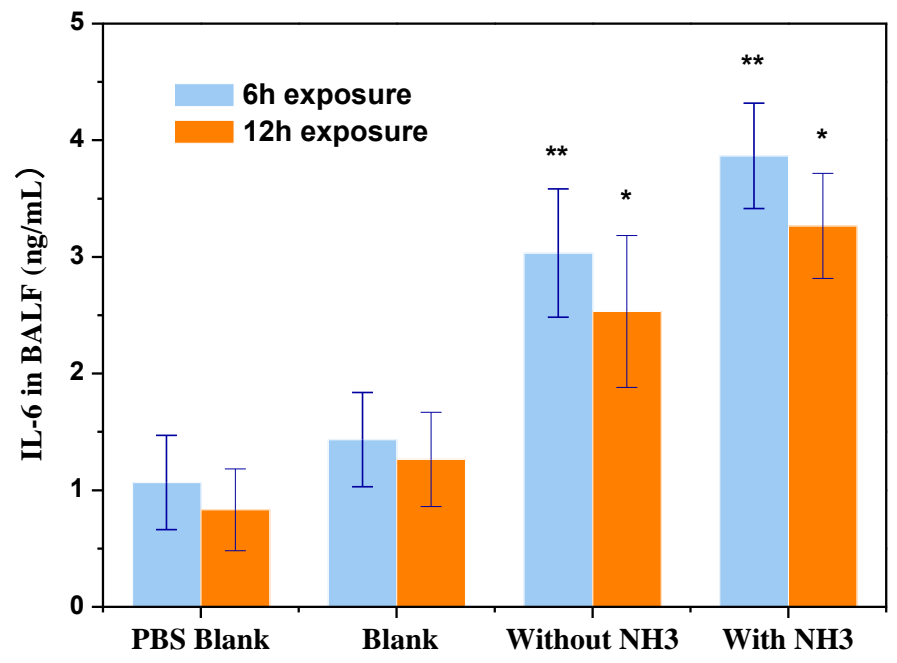

(c)

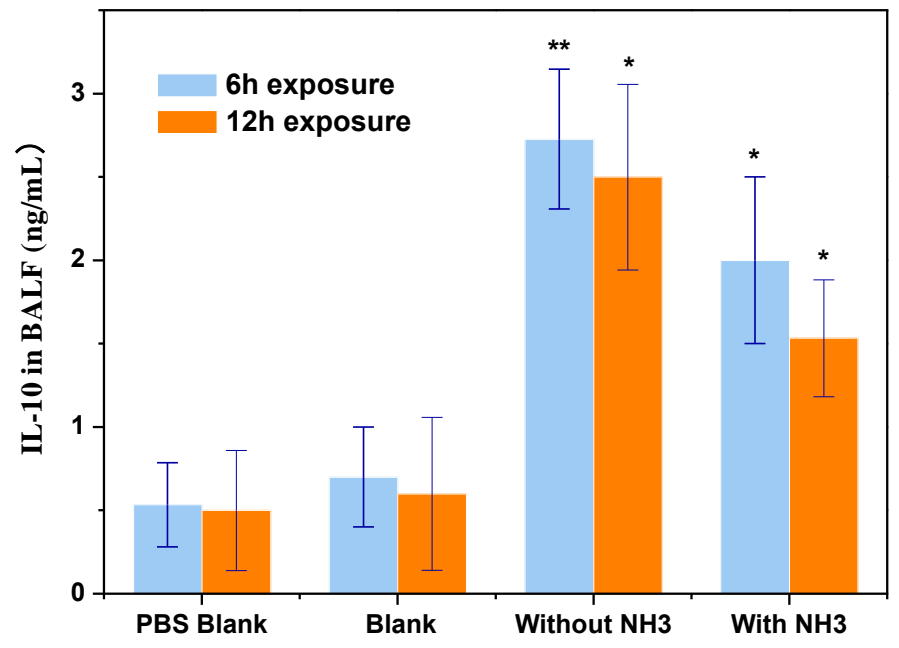

Fig. 5 Effects of $\mathrm{NH}_{3}$ on (a) TNF- $\alpha$; (b) IL-6; (c) IL-10 levels in ozone and monoterpene reactions. ${ }^{*} \mathrm{p}<0.05,{ }^{* *} \mathrm{p}<0.01$

TNF- $\alpha$ is a representative and pleiotropic proinflammatory cytokine in the 
inflammation response. It stimulates the expression of COX-2 and iNOS and triggers inflammation, injury and carcinogenesis in various tissues (Goldring and Goldring, 2004). Another significant proinflammatory cytokine is IL-6, which is generated by different cells and possesses pleiotropic effects on different tissues. IL-6 regulates genes expression involved in cell cycle progression and suppression of apoptosis (Lin and Karin, 2007). In present study, it was found that the levels of TNF- $\alpha$ and IL-6 in BALF was significantly increased after PM samples instillation with and without $\mathrm{NH}_{3}$ presence compared with blank groups, the results are consistent with previous observations where particles from different sources trigger pulmonary inflammation (Dick et al., 2003; Perez et al., 2007). In the reactions of ozone and monoterpene with the presence of $\mathrm{NH}_{3}$, the proinflammatory cytokine levels was increased comparing to reactions without $\mathrm{NH}_{3}$ when induced the same dose of PM suspensions, which indicated that the effect of $\mathrm{NH}_{3}$ not only has enhanced the generations of SOAs, but also increased the probabilities of cell injury or cell death, and pulmonary inflammation, injury or carcinogenesis would be triggered more easily, which may caused by the new generated chemical species with enhanced toxicity.

IL-10, a significant anti-inflammatory cytokine, is characterized by anti-inflammatory and immunosuppressive activities. IL-10 acts in a pleiotropic way by inhibiting antigen presentation, decreasing cell-surface expression of cytokine receptors and inducing expression of endogenous cytokine antagonists (Rennick and Fort, 2000). In this study, the production of IL-10 in BALF was found to be notably 
reduced in ozone and monoterpene reactions with the presence of $\mathrm{NH}_{3}$ comparing to the reactions without $\mathrm{NH}_{3}$, which indicated that the effect of $\mathrm{NH}_{3}$ in the reactions would weaken the anti-inflammatory abilities of cells and tissues, with weak defense, inflammation, injury and carcinogenesis on mice lung would be happened in greater chances.

Generally, particles undergo a variety of physicochemical transformations during their transport from sources to receptors, resulting in the formation of secondary inorganic and organic PM species. In our study, large amount of secondary organic aerosols were generated from the chemical and physical reactions between $\mathrm{O}_{3}$ and monoterpenes, and $\mathrm{NH}_{3}$ drives gas-phase organic acids into particle-phase organics which enhanced SOAs generations. Recently more and more researches have focus on the toxicity of secondary particles, they found that the most significant responses always occurred in more complex oxidized scenarios, which indicated that photochemically aged particles are more toxic than primary particles (Diaz et al., 2011; Godleski et al., 2011; Lemos et al., 2011; Verma et al., 2009; Wellenius et al., 2011). The responses included increases in in vivo chemiluminescence of the heart and the lung, change in breathing patterns, increases in total cell count and macrophage number on bronchoalveolar lavage, and the increases of pro-inflammation cytokines and reactive oxygen species (ROS). In addition, Delfino et al. (2010) concluded that organic components were more strongly and significantly associated with systemic inflammation, whereas organic components related to secondary photochemical aging of particles were more strongly and 
significantly associated with airway inflammation.

In conclusion, above in vivo results suggest that inflammatory cytokines of TNF- $\alpha$, IL-6, and IL-10 may be responsible for the effects observed with different PM suspensions. SOAs from reactions of ozone and monoterpene with the presence of $\mathrm{NH}_{3}$ from the simulated indoor environment induced the potent inflammatory reaction upon intratracheal instillation in mice lung, meanwhile particles from reactions without the presence of $\mathrm{NH}_{3}$ could also induce pulmonary inflammatory with weaker effects. However, it remains to be investigated whether the in vivo effects as observed with PM samples simulated from different conditions from this study also hold true for samples from other reactions and conditions. In addition, considering the complexity of particle composition related to multiple kinds of reactions with varies SOAs, it is still not easy to separate which components are responsible for activating the molecular mechanisms able to induce TNF-a , IL-6 and IL-10 secretion, which need a combination and initial correlation studies on characteristics of different chemical composition and size distribution-specific activities with inflammation effects.

\section{Conclusions}

This research focuses on the indoor ozone-initiated SOAs formation of d-limonene in the large environmental chamber. Based on the experimental results, the formation characteristics, effects of $\mathrm{NH}_{3}$ existence, and potential pulmonary injuries from the ozonolysis were well investigated. Our results demonstrated that the presence of $\mathrm{NH}_{3}$ indoor could significantly enhance the SOAs formation and increase the mean 
particle diameters during the reactions between $\mathrm{O}_{3}$ and d-limonene. Both of the nuclei coagulation and condensation take parts in the growth of SOAs. Besides, the $\mathrm{NH}_{3}$ atmosphere could lead the formation of more toxic $\mathrm{PM}$, evidencing with higher levels of TNF- $\alpha$ and IL-6 factors, while the anti-inflammatory cytokine of IL-10 was also reduced during the exposure to $\mathrm{NH}_{3}$. Our results conclude that the SOAs formed from the ozonolysis of monoterpene in the presence of $\mathrm{NH}_{3}$ could potentially induce the potent inflammatory reaction upon intratracheal instillation in mice lung. The finding is critical for further IAQ researches.

\section{Acknowledgement}

This research was financially supported by the National Science Foundation of China (41401567, 41573138) and the "Strategic Priority Research Program" of the Chinese Academy of Sciences (Grant No. XDB05000000), and was also partially supported by the Research Grants Council of the Hong Kong Special Administrative Region China (Project No. CUHK 412612). Yu Huang is also supported by the "Hundred Talent Program" of the Chinese Academy of Sciences. 


\section{References}

Astort, F., Sittner, M., Ferraro, S.A., Orona, N.S., Maglione, G.A., De la Hoz, A., Tasat, D.R., 2014. Pulmonary Inflammation and Cell Death in Mice After Acute Exposure to Air Particulate Matter From an Industrial Region of Buenos Aires. Archives of Environmental Contamination and Toxicology 67, 87-96.

Bai, Z., Dong, Y., Wang, Z., Zhu, T., 2006. Emission of ammonia from indoor concrete wall and assessment of human exposure. Environment International 32, 303-311.

Bates, J.T., Weber, R.J., Abrams, J., Verma, V., Fang, T., Klein, M., Strickland, M.J., Sarnat, S.E., Chang, H.H., Mulholland, J.A., Tolbert, P.E., Russell, A.G., 2015. Reactive Oxygen Species Generation Linked to Sources of Atmospheric Particulate Matter and Cardiorespiratory Effects. Environmental Science \& Technology 49, 13605-13612.

Breysse, P.N., Delfino, R.J., Dominici, F., Elder, A.C.P., Frampton, M.W., Froines, J.R., Geyh, A.S., Godleski, J.J., Gold, D.R., Hopke, P.K., Koutrakis, P., Li, N., Oberdorster, G., Pinkerton, K.E., Samet, J.M., Utell, M.J., Wexler, A.S., 2013. US EPA particulate matter research centers: summary of research results for 2005-2011. Air Quality Atmosphere and Health 6, 333-355.

Britigan, N., Alshawa, A., Nizkorodov, S.A., 2006. Quantification of ozone levels in indoor environments generated by ionization and ozonolysis air purifiers. Journal of the Air \& Waste Management Association 56, 601-610.

Brown, S.K., Sim, M.R., Abramson, M.J., Gray, C.N., 1994. Concentrations of Volatile Organic Compounds in Indoor Air - A Review. Indoor Air 4, 123-134.

Cao, J.J., Xu, H.M., Xu, Q., Chen, B.H., Kan, H.D., 2012. Fine Particulate Matter Constituents and Cardiopulmonary Mortality in a Heavily Polluted Chinese City. Environmental Health Perspectives 120, 373-378.

Che, W.W., Frey, H.C., Lau, A.K.H., 2015. Comparison of Sources of Variability in School Age Children Exposure to Ambient PM2.5. Environmental Science \& Technology 49, 1511-1520.

Chen, X., Hopke, P.K., 2010. A chamber study of secondary organic aerosol formation by limonene ozonolysis. Indoor Air 20, 320-328.

de Brito, J.M., Macchione, M., Yoshizaki, K., Toledo-Arruda, A.C., Saraiva-Romanholo, B.M., Andrade, M.d.F., Mauad, T., Rivero, D.H.R.F., Saldiva, P.H.N., 2014. Acute cardiopulmonary effects induced by the inhalation of concentrated ambient particles during seasonal variation in the city of Sao Paulo. Journal of applied physiology (Bethesda, Md. : 1985) 117, 492-499.

Delfino, R.J., Staimer, N., Tjoa, T., Arhami, M., Polidori, A., Gillen, D.L., George, S.C., Shafer, M.M., Schauer, J.J., Sioutas, C., 2010. Associations of Primary and Secondary Organic Aerosols With Airway and Systemic Inflammation in an Elderly Panel Cohort. Epidemiology 21, 892-902.

Destaillats, H., Lunden, M.M., Singer, B.C., Coleman, B.K., Hodgson, A.T., Weschler, C.J., Nazaroff, W.W., 2006. Indoor secondary pollutants from household product emissions in the presence of ozone: A bench-scale chamber study. Environmental Science \& Technology 40, 4421-4428.

Diaz, E.A., Lemos, M., Coull, B., Long, M.S., Rohr, A.C., Ruiz, P., Gupta, T., Kang, C.M., Godleski, J.J., 2011. Toxicological Evaluation of Realistic Emission Source Aerosols (TERESA)-Power plant studies: assessment of breathing pattern. Inhalation Toxicology 23, 42-59.

Dick, C.A.J., Singh, P., Daniels, M., Evansky, P., Becker, S., Gilmour, M.I., 2003. Murine pulmonary inflammatory responses following instillation of size-fractionated ambient particulate matter. Journal of Toxicology and Environmental Health-Part A 66, 2193-2207. 
Farina, F., Sancini, G., Mantecca, P., Gallinotti, D., Camatini, M., Palestini, P., 2011. The acute toxic effects of particulate matter in mouse lung are related to size and season of collection. Toxicology Letters 202, 209-217.

Godish, T.J., 1989. Indoor Air Pollution Control. MI, USA.

Godleski, J.J., Diaz, E.A., Lemos, M., Long, M., Ruiz, P., Gupta, T., Kang, C.M., Coull, B., 2011. Toxicological Evaluation of Realistic Emission Source Aerosols (TERESA)-power plant studies: assessment of cellular responses. Inhalation Toxicology 23, 60-74.

Goldring, S.R., Goldring, M.B., 2004. The role of cytokines in cartilage matrix degeneration in osteoarthritis. Clinical Orthopaedics and Related Research, S27-S36.

He, G.L., Ying, B., Liu, J., Gao, S.R., Shen, S., Balakrishnan, K., Jin, Y.L., Liu, F., Tang, N., Shi, K., Baris, E., Ezzati, M., 2005. Patterns of household concentrations of multiple indoor air pollutants in China. Environmental Science \& Technology 39, 991-998.

Ho, K.F., Ho, S.S.H, Huang, R.J., Chuang, H.C., Cao, J.J., Han, Y.M., Lui, K.H., Ning, Z., Chuang, K.J., Cheng, T.J., Lee., S.C., Hu, D., Wang, B., Zhang, R.J., 2016. Chemical composition and bioreactivity of PM2.5 during 2013 haze events in China. Atmospheric Environment 126, $162-170$.

Huang, W., Cao, J.J., Tao, Y.B., Dai, L.Z., Lu, S.E., Hou, B., Wang, Z., Zhu, T., 2012a. Seasonal Variation of Chemical Species Associated With Short-Term Mortality Effects of PM2.5 in Xi'an, a Central City in China. American Journal of Epidemiology 175, 556-566.

Huang, Y., Ho, K.F., Ho, S.S.H., Lee, S.C., Yau, P.S., Cheng, Y., 2011a. Physical parameters effect on ozone-initiated formation of indoor secondary organic aerosols with emissions from cleaning products. Journal of Hazardous Materials 192, 1787-1794.

Huang, Y., Ho, S.S.H., Ho, K.F., Lee, S.C., Gao, Y., Cheng, Y., Chan, C.S., 2011b. Characterization of biogenic volatile organic compounds (BVOCs) in cleaning reagents and air fresheners in Hong Kong. Atmospheric Environment 45, 6191-6196.

Huang, Y., Lee, S.C., Ho, K.F., Ho, S.S.H., Cao, N.Y., Cheng, Y., Gao, Y., 2012b. Effect of ammonia on ozone-initiated formation of indoor secondary products with emissions from cleaning products. Atmospheric Environment 59, 224-231.

Institute of Laboratory Animal Resources, Committee on Care Use of Laboratory Animals, National Institutes of Health, Resources, D.o.R., 1985. Guide for the care and use of laboratory animals. National Academies.

Jiang, R.T., Bell, M.L., 2008. A comparison of particulate matter from biomass-burning rural and non-biomass-burning urban households in northeastern China. Environmental Health Perspectives 116, 907-914.

Jones, N.C., Thornton, C.A., Mark, D., Harrison, R.M., 2000. Indoor/outdoor relationships of particulate matter in domestic homes with roadside, urban and rural locations. Atmospheric Environment 34, 2603-2612.

Kavouras, I.G., Mihalopoulos, N., Stephanou, E.G., 1999. Formation and gas/particle partitioning of monoterpenes photo-oxidation products over forests. Geophysical Research Letters 26, 55-58.

Koistinen, K., Kotzias, D., Kephalopoulos, S., Schlitt, C., Carrer, P., Jantunen, M., Kirchner, S., McLaughlin, J., Molhave, L., Fernandes, E.O., Seifert, B., 2008. The INDEX project: executive summary of a European Union project on indoor air pollutants. Allergy 63, 810-819.

Lamorena, R.B., Lee, W., 2008. Influence of ozone concentration and temperature on ultra-fine particle and gaseous volatile organic compound formations generated during the ozone-initiated 
reactions with emitted terpenes from a car air freshener. Journal of Hazardous Materials 158, 471-477.

Lemos, M., Diaz, E.A., Gupta, T., Kang, C.M., Ruiz, P., Coull, B.A., Godleski, J.J., Gonzalez-Flecha, B., 2011. Cardiac and pulmonary oxidative stress in rats exposed to realistic emissions of source aerosols. Inhalation Toxicology 23, 75-83.

Leung, P.Y., Wan, H.T., Billah, M.B., Cao, J.J., Ho, K.F., Wong, C.K.C., 2014. Chemical and biological characterization of air particulate matter 2.5, collected from five cities in China. Environmental Pollution 194, 188-195.

Leungsakul, S., Jeffries, H.E., Kamens, R.M., 2005. A kinetic mechanism for predicting secondary aerosol formation from the reactions of d-limonene in the presence of oxides of nitrogen and natural sunlight. Atmospheric Environment 39, 7063-7082.

Lin, M., Stieb, D.M., Chen, Y., 2005. Coarse particulate matter and hospitalization for respiratory infections in children younger than 15 years in Toronto: A case-crossover analysis. Pediatrics 116, E235-E240.

Lin, W.-W., Karin, M., 2007. A cytokine-mediated link between innate immunity, inflammation, and cancer. Journal of Clinical Investigation 117, 1175-1183.

Madureira, J., Paciencia, I., Rufo, J., Ramos, E., Barros, H., Teixeira, J.P., Fernandes, E.D., 2015. Indoor air quality in schools and its relationship with children's respiratory symptoms. Atmospheric Environment 118, 145-156.

Magnani, N.D., Marchini, T., Tasat, D.R., Alvarez, S., Evelson, P.A., 2011. Lung oxidative metabolism after exposure to ambient particles. Biochemical and Biophysical Research Communications 412, 667-672.

Michael, S., Montag, M., Dott, W., 2013. Pro-inflammatory effects and oxidative stress in lung macrophages and epithelial cells induced by ambient particulate matter. Environmental Pollution $183,19-29$.

Mirowsky, J., Hickey, C., Horton, L., Blaustein, M., Galdanes, K., Peltier, R.E., Chillrud, S., Chen, L.C., Ross, J., Nadas, A., Lippmann, M., Gordon, T., 2013. The effect of particle size, location and season on the toxicity of urban and rural particulate matter. Inhalation Toxicology 25, 747-757.

Na, K., Song, C., Cocker, D.R., 2006. Formation of secondary organic aerosol from the reaction of styrene with ozone in the presence and absence of ammonia and water. Atmospheric Environment 40, 1889-1900.

Na, K., Song, C., Switzer, C., Cocker, D.R., 2007. Effect of ammonia on secondary organic aerosol formation from alpha-Pinene ozonolysis in dry and humid conditions. Environmental Science \& Technology 41, 6096-6102.

Nazaroff, W.W., Weschler, C.J., 2004. Cleaning products and air fresheners: exposure to primary and secondary air pollutants. Atmospheric Environment 38, 2841-2865.

Ostachuk, A., Evelson, P., Martin, S., Dawidowski, L., Yakisich, J.S., Tasat, D.R., 2008. Age-related lung cell response to urban Buenos Aires air particle soluble fraction. Environmental Research 107, 170-177.

Parker, J.L., Larson, R.R., Eskelson, E., Wood, E.M., Veranth, J.M., 2008. Particle size distribution and composition in a mechanically ventilated school building during air pollution episodes. Indoor Air 18, 386-393.

Perez, I.R., Serrano, J., Alfaro-Moreno, E., Baumgardner, D., Garcia-Cuellar, C., del Campo, J.M.M., Raga, G.B., Castillejos, M., Colin, R.D., Vargas, A.R., 2007. Relations between PM10 
composition and cell toxicity: A multivariate and graphical approach. Chemosphere 67, 1218-1228.

Pei, J. J., Yin, Y. H., Liu, J. J., 2016. Long-term indoor gas pollutant monitor of new dormitories with natural ventilation. Energy and Buildings 129, 514-523.

Rennick, D.M., Fort, M.M., 2000. Lessons from genetically engineered animal models - XII. IL-10-deficient (IL-10(-/-)) mice and intestinal inflammation. American Journal of Physiology-Gastrointestinal and Liver Physiology 278, G829-G833.

Rohr, A.C., Wilkins, C.K., Clausen, P.A., Hammer, M., Nielsen, G.D., Wolkoff, P., Spengler, J.D., 2002. Upper airway and pulmonary effects of oxidation products of (+)-alpha-pinene, d-limonene, and isoprene in BALB/c mice. Inhalation Toxicology 14, 663-684

Rossignol, S., Rio, C., Ustache, A., Fable, S., Nicolle, J., Meme, A., D'Anna, B., Nicolas, M., Leoz, E., Chiappini, L., 2013. The use of a housecleaning product in an indoor environment leading to oxygenated polar compounds and SOA formation: Gas and particulate phase chemical characterization. Atmospheric Environment 75, 196-205.

Sarigiannis, D.A., Karakitsios, S.P., Gotti, A., Liakos, I.L., Katsoyiannis, A., 2011. Exposure to major volatile organic compounds and carbonyls in European indoor environments and associated health risk. Environment International 37, 743-765.

Sarwar, G., Corsi, R., 2007. The effects of ozone/limonene reactions on indoor secondary organic aerosols. Atmospheric Environment 41, 959-973.

Seagrave, J., McDonald, J.D., Bedrick, E., Edgerton, E.S., Gigliotti, A.P., Jansen, J.J., Ke, L., Naeher, L.P., Seilkop, S.K., Zheng, M., Mauderly, J.L., 2006. Lung toxicity of ambient particulate matter from southeastern US sites with different contributing sources: Relationships between composition and effects. Environmental Health Perspectives 114, 1387-1393.

Singer, B.C., Coleman, B.K., Destaillats, H., Hodgson, A.T., Lunden, M.M., Weschler, C.J., Nazaroff, W.W., 2006a. Indoor secondary pollutants from cleaning product and air freshener use in the presence of ozone. Atmospheric Environment 40, 6696-6710.

Singer, B.C., Destaillats, H., Hodgson, A.T., Nazaroff, W.W., 2006b. Cleaning products and air fresheners: emissions and resulting concentrations of glycol ethers and terpenoids. Indoor Air 16, 179-191.

Tamas, G., Weschler, C.J., Toftum, J., Fanger, P.O., 2006. Influence of ozone-limonene reactions on perceived air quality. Indoor Air 16, 168-178.

USEPA, 1999. Large Chamber Test Protocol for Measuring Emissions of VOCs and Aldehydes. Research Triangle Park, North Carolina.

Verma, V., Ning, Z., Cho, A.K., Schauer, J.J., Shafer, M.M., Sioutas, C., 2009. Redox activity of urban quasi-ultrafine particles from primary and secondary sources. Atmospheric Environment 43, 6360-6368.

Waring, M.S., Siegel, J.A., 2011a. The effect of an ion generator on indoor air quality in a residential room. Indoor Air 21, 267-276.

Waring, M.S., Siegel, J.A., 2013. Indoor Secondary Organic Aerosol Formation Initiated from Reactions between Ozone and Surface-Sorbed D-Limonene. Environmental Science \& Technology 47, 6341-6348.

Waring, M.S., Wells, J.R., Siegel, J.A., 2011b. Secondary organic aerosol formation from ozone reactions with single terpenoids and terpenoid mixtures. Atmospheric Environment 45, 4235-4242. 
Wellenius, G.A., Diaz, E.A., Gupta, T., Ruiz, P.A., Long, M., Kang, C.M., Coull, B.A., Godleski, J.J., 2011. Electrocardiographic and respiratory responses to coal-fired power plant emissions in a rat model of acute myocardial infarction: results from the Toxicological Evaluation of Realistic Emissions of Source Aerosols Study. Inhalation Toxicology 23, 84-94.

Weschler, C.J., 2006. Ozone's impact on public health: Contributions from indoor exposures to ozone and products of ozone-initiated chemistry. Environmental Health Perspectives 114, 1489-1496.

Wilkins, C.K., Wolkoff, P., Clausen, P.A., Hammer, M., Nielsen, G.D., 2003. Upper airway irritation of terpene/ozone oxidation products (TOPS). Dependence on reaction time, relative humidity and initial ozone concentration. Toxicology Letters 143, 109-114.

Yu, J.Z., Griffin, R.J., Cocker, D.R., Flagan, R.C., Seinfeld, J.H., Blanchard, P., 1999. Observation of gaseous and particulate products of monoterpene oxidation in forest atmospheres. Geophysical Research Letters 26, 1145-1148.

Zhou, Z. H., Liu, Y. R., Yuan, J. J., Zuo, J., Chen, G. Y., Xu, L. Y., Rameezdeen, R.. 2016. Indoor PM2.5 concentrations in residential buildings during a severely polluted winter: A case study in Tianjin, China. Renewable \& Sustainable Energy Reviews 64: 372-381. 


\section{Graphical Abstract}

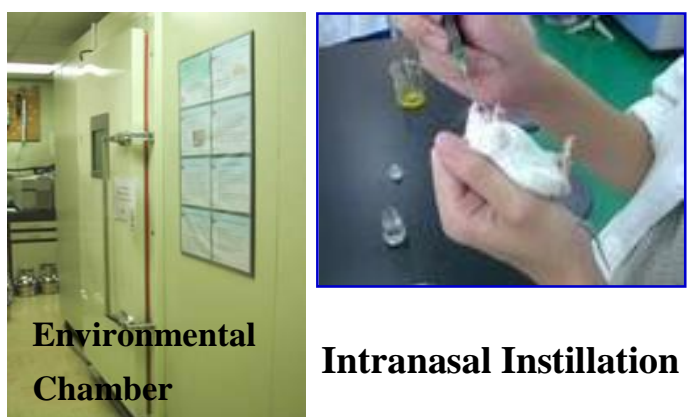

